\title{
Does COVID-19 affect male fertility?
}

\author{
Anis Abobaker ${ }^{1} \cdot$ Ali Ahmed Raba² ${ }^{2}$
}

Received: 6 April 2020 / Accepted: 8 April 2020 / Published online: 21 April 2020

(c) Springer-Verlag GmbH Germany, part of Springer Nature 2020

\section{Dear Editor,}

Multiple cases of pneumonia caused by a novel corona virus (SARS-COV2) have been reported in Wuhan city in China in December 2019 [1]. Since then, the infection has spread world-wide, leading to acute respiratory distress syndrome (SARS) named as "COVID-19" by the World Health Organization (WHO) [1]. On 11/03/2020, the disease has been declared as a global pandemic by WHO [1]. Angiotensin converting enzymes 2 (ACE2) receptors play a key role in pathogenesis of COVID-19. Binding of SARS-COV2 virus to ACE2 receptors facilitate its cell entry and replication [2]. Therefore, cells that show high level of ACE2 expression have the potential to be targeted and damaged by the virus [2]. Multiple studies detected high ACE2 expression level in testicular cells, mainly in seminiferous duct cells, spermatogonia, Leydig cell and Sertoli cells [2-4]. Based on the results of these studies, it is concluded that the testis could be a potential target for direct damage by SARS-COV2 virus. Another study performed following the outbreak of SARS-COV infection in 2002 showed that orchitis was a recognised complication of SARS [5]. The main question is whether COVID-19 has the potential to cause testicular damage and infertility in male patients. So far there is no definitive answer as a follow-up of reproductive function of recovered male patients is required.

SARS-cov2 virus binds to ACE2 receptors and enter the cells to complete its replication cycle [2]. This is considered as the main pathological mechanism of direct cell infection and damage by the virus. Therefore, cells with increased ACE2 expression are potential target of viral invasion [2]. Among different body tissues, testis shows nearly the highest level of ACE2 mRNA and protein expression [2]. At

Ali Ahmed Raba

ali.raba@ucdconnect.ie

1 Spire Fylde Coast Hospital, Blackpool, UK

2 UCD School of Medicine and Medical Sciences, Dublin, Ireland the level of testicular cells, four main cell types; seminiferous duct cells, spermatogonia, Leydig cells and Sertoli cells, show higher rate of ACE2 mRNA expression [2-4]. If the virus causes damage to these cells, the process of spermatogenesis could be affected which might pose risk to male fertility. Interestingly, the testicular expression of ACE2 is age related [4]. The highest expression recorded in patients aged 30, which is higher than those in their twenties, whereas 60-year-old patients show the lowest level of expression [4]. This might indicate that young male patients are at higher risk of testicular damage by COVID-19 than older patients. In one study, examination of autopsy specimen of testis of six patients who died due to SARS-Cov infection in 2002 showed an evidence of orchitis [5]. Histopathological examination revealed inflammatory infiltrates, mainly in seminiferous tubules [5]. Immunohistochemistry showed IgG deposition mainly in seminiferous epithelium, interstitium, degenerated germ cells and Sertoli cells [5]. These are almost the same cell types that show high ACE2 expression [2-4]. Interestingly, in-situ hybridization does not detect viral genomic materials in the testicular tissue specimens [5]. This indicates that testicular damage is due to inflammatory and immunological response rather than direct damage by the virus.

There is a theoretical possibility of testicular damage and subsequent infertility following COVID-19 infection. The possibility of testicular damage is caused by either direct viral invasion through binding of SARS-COV2 virus to ACE2 receptors or secondary to immunological and inflammatory response. Follow-up studies of reproductive function of recovered male patients is required to investigate this possibility.

Author contributions AA designed the study and drafted the initial manuscript. AAR reviewed and revised the manuscript for important intellectual content. 
Funding No financial or nonfinancial benefits have been received or will be received from any party related directly or indirectly to the subject of this article.

\section{Compliance with ethical standards}

Conflict of interest The authors declare that they have no conflicts of interest.

Research involving human participants and/or animals This article does not contain any studies with human participants or animals performed by any of the authors.

Informed consent No informed consent was needed.

\section{Reference}

1. Who.int (2020) Coronavirus disease (COVID-19)—events as they happen. https://www.who.int/emergencies/diseases/novel-coron
avirus-2019/events-as-they-happen?fbclid=IwAR2_cYFiF9cPKu bBCvhuLADnFpS7P1FmqL1M0TicVGPOw5ngB37EuZozQ4U . Accessed 31 Mar 2020

2. Fan C, Li K, Ding Y, Lu W, Wang J (2020) ACE2 expression in kidney and testis may cause kidney and testis damage after 2019nCoV infection, medRxiv

3. Wang Z, Xu X (2020) scRNA-seq Profiling of Human Testes Reveals the Presence of ACE2 Receptor, a Target for SARS-CoV-2 Infection, in Spermatogonia, Leydig and Sertoli Cells. medRxiv

4. Shen Q, Xiao X, Aierken A, Liao M, Hua J (2020) The ACE2 expression in Sertoli cells and germ cells may cause male reproductive disorder after SARS-CoV-2 infection. medRxiv

5. Xu J, Qi L, Chi X, Yang J, Wei X, Gong E, Peh S, Gu J (2006) Orchitis: a complication of severe acute respiratory syndrome (SARS)1. Biol Reprod 74(2):410-416

Publisher's Note Springer Nature remains neutral with regard to jurisdictional claims in published maps and institutional affiliations. 